\title{
Correlation of subsurface damage and surface roughness on ZERODUR ground surfaces by using rotation table peripheral grinding process
}

\author{
Antoine Leys, Tony Hull, Antoine Carré, Thomas \\ Westerhoff
}

Antoine Leys, Tony B. Hull, Antoine Carré, Thomas Westerhoff, "Correlation of subsurface damage and surface roughness on ZERODUR ground surfaces by using rotation table peripheral grinding process," Proc. SPIE 11852, International Conference on Space Optics - ICSO 2020, 118522I (11 June 2021); doi: 10.1117/12.2599381 SPIE. Event: International Conference on Space Optics - ICSO 2021, 2021, Online 


\section{International Conference on Space Optics-ICSO 2020}

Virtual Conference

30 March-2 April 2021

Edited by Bruno Cugny, Zoran Sodnik, and Nikos Karafolas
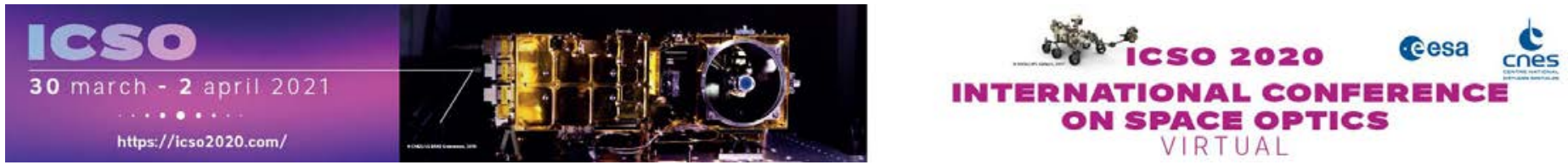

\section{Correlation of subsurface damage and surface roughness on ZERODUR ground surfaces by using rotation table peripheral grinding process}

\section{Cesa issopecestings ecnes}




\title{
Correlation of subsurface damage and surface roughness on ZERODUR ${ }^{\circledR}$ ground surfaces by using rotation table peripheral grinding process
}

\author{
Antoine Leys ${ }^{1 *}$, Tony Hull ${ }^{2}$, Antoine Carré ${ }^{1}$, Thomas Westerhoff ${ }^{1}$ \\ ${ }^{1}$ Schott AG, Advanced Optics, D-55122 Mainz \\ ${ }^{2}$ University of New Mexico, Albuquerque, NM 87131, USA \\ 27.01.2021
}

\begin{abstract}
ZERODUR ${ }^{\circledR}$ surfaces resulting from machining to spherical or aspherical forms have been investigated by visible light microscopy to identify subsurface damage (SSD). The rotation table peripheral grinding method has been used. Surface roughness (SR) of the different finished surfaces has been measured by a profilometer. We then examine the correlation between subsurface damage and roughness. This correlation allows for a precise determination and reduction of the SSD, enabling subsequent process steps such as polishing to continue with finer tool sizes resulting in a more efficient overall process.
\end{abstract}

Keywords: ZERODUR ${ }^{\circledR}$, subsurface damage (SSD), surface roughness (SR), sphere, grinding, diamond tool.

\section{INTRODUCTION}

Subsurface damage (SSD) refers to the residual fractured and deformed material in the near-surface region of brittle optical materials. This layer of deformed and fractured material is generally the result of abrasive cutting, grinding and lapping operations that are typically used during the initial shaping of optical components. During shaping, SSD is minimized by the use of a series of grinding steps where successively smaller abrasives are used to remove the subsurface damage introduced during previous grinding or lapping operations. The final vestiges of SSD from grinding and lapping can be removed by polishing, provided that sufficient material can be removed without introducing additional SSD during the polishing process [1-8]. A detailed understanding of the introduced SSD during each operational step is necessary in order to optimize the overall manufacturing of an optical component. The control and continuous reduction of the SSD during the grinding process, allows the use of small deterministic tools at the beginning of the subsequent polishing. Furthermore, the use of large-sized polishing tools that introduce quilting of the surface can be omitted from the process. This results in a more efficient preparation of the optical surface reducing the overall process risk. The first goal of this work is to investigate the depth of the subsurface damage for different grinding operations (rough, semi-finished and finished) for shaping a sphere in the manner to optimize the number of sequential different grinding steps, while determining the extent of subsurface damage which is induced by the last grinding step. The second goal of this work is to find a correlation between SSD and roughness. In fact, SSD determination is a destructive process whereas roughness measurement is a nondestructive process. If a correlation between SSD and surface roughness (SR) is found, the SSD of a finished surface can be determined without destruction of the piece. With proper tribological processes during fixed abrasive finishing, SSD to be removed by loose abrasive optical processes can be minimized to be of the same order of magnitude as milled aspheric "form error" on the mirror surface, presently of the order of $25 \mu \mathrm{m}$. This offers significant reductions in optical fabrication efforts, especially so for lightweighted mirrors, since quilting is not then introduced by the optical processes. 


\section{EXPERIMENTAL DETAILS}

Four ZERODUR ${ }^{\circledR}$ work pieces have been ground with different diamond grain sizes on a 4 axis machine (Kehren). The applied process is "peripheral grinding with table rotation" typically used to shape sphere or asphere of a mirror (see Figure $1)$.
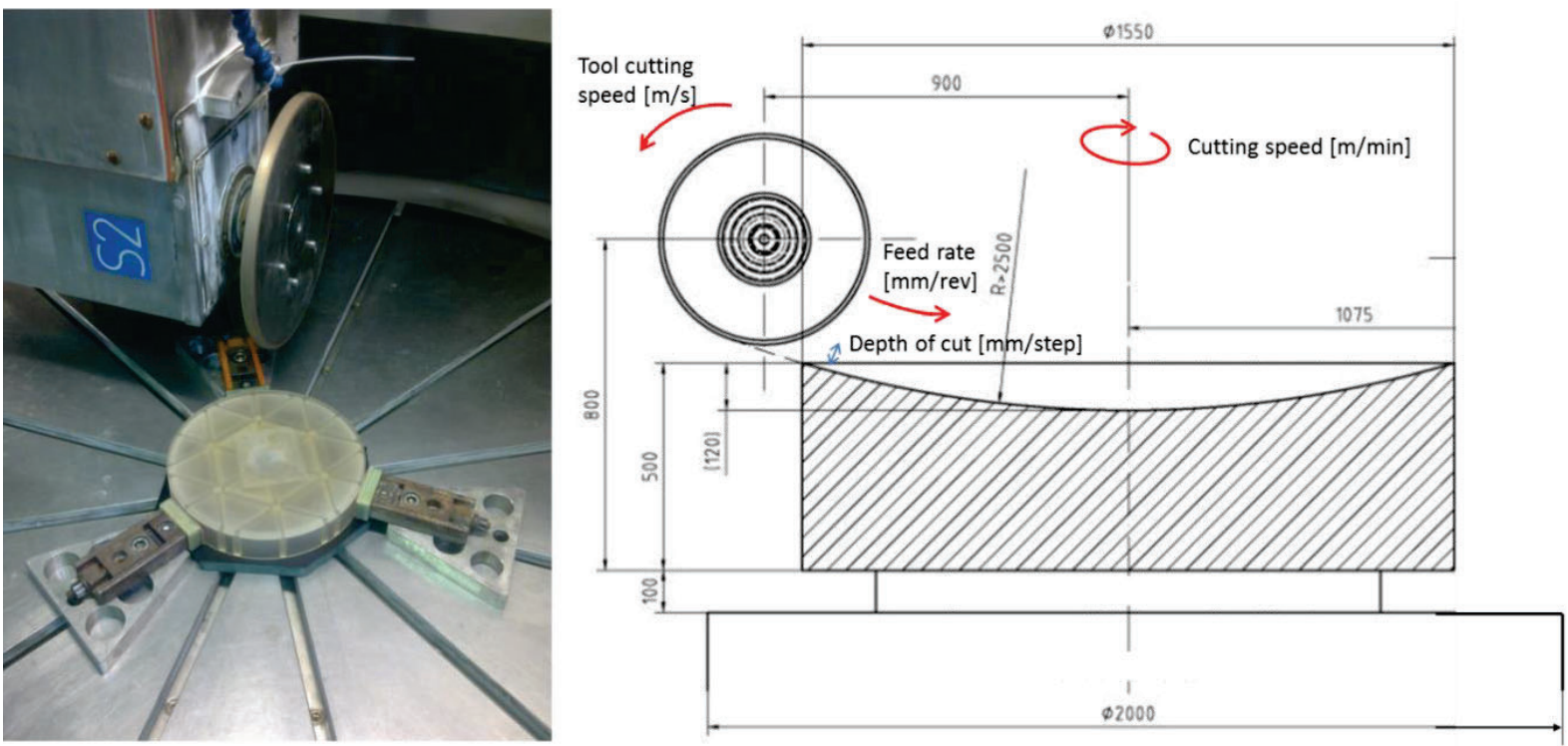

Figure 1. Table rotation peripheral grinding.

To achieve a ground surface with the high cutting speed Vc, the small ZERODUR ${ }^{\circledR}$ part has been fixed off-axis on the machine table. Each ZERODUR ${ }^{\circledR}$ part has been parted afterwards into 20 samples. The analyzed lines of 10 samples are tangential and 10 samples are radial (see Figure 2). The plates are fixed simultaneous at an angle of $90^{\circ}$. 


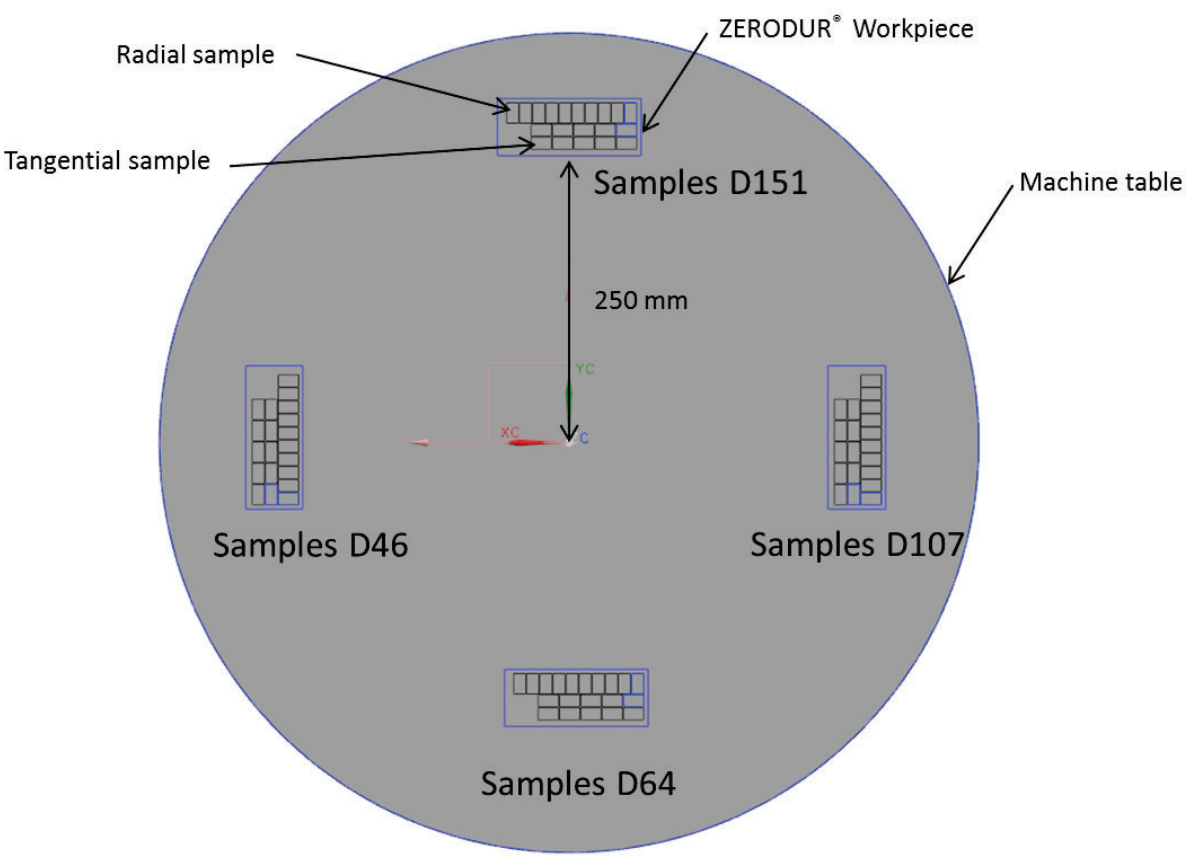

Figure 2. Position of the fixation of the ZERODUR ${ }^{\circledR}$ plate on the machine table and position of the samples in the ZERODUR ${ }^{\circledR}$ plate.

The samples are cuboids of $50 \times 30 \times 5 \mathrm{~mm}$ with a $2 \mathrm{~mm}$ depth groove on the backside of the analyzed surface (see Figure 3 ). Each sample has been marked on both sides from 1 till 10 and with the letter $\mathrm{R}$ for radial and $\mathrm{T}$ for tangential. The diamond tool grain size of the last step is also marked (see Figure 4). The samples (Figure 4) have been broken along the groove with two a pair of pliers so that the analyzed surfaces do not carry any tensile stress, which would increase the size of the SSD. The samples have been analyzed with a microscope (x50).

For this test, the sphere radius $\mathrm{r}+\infty$ has been programmed to have a plano-plano surface, which simplifies the shape of the samples and keeps constant the thickness of the samples.
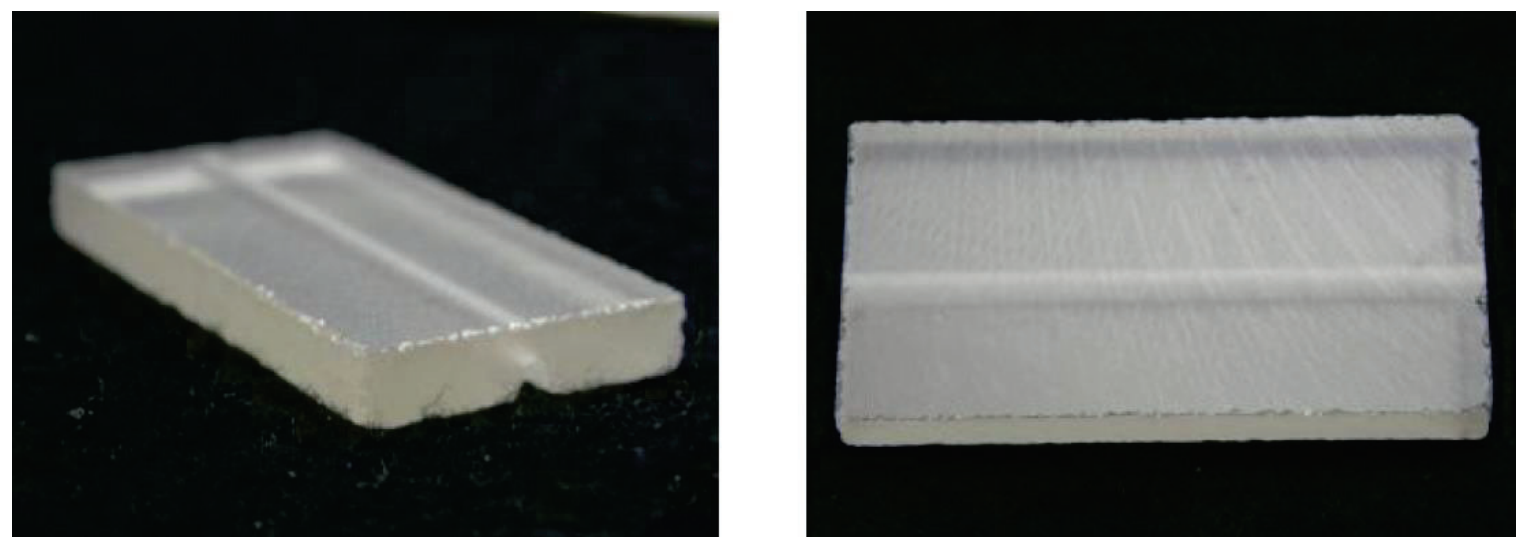

Figure 3. Photography illustrating a sample before breakage. 


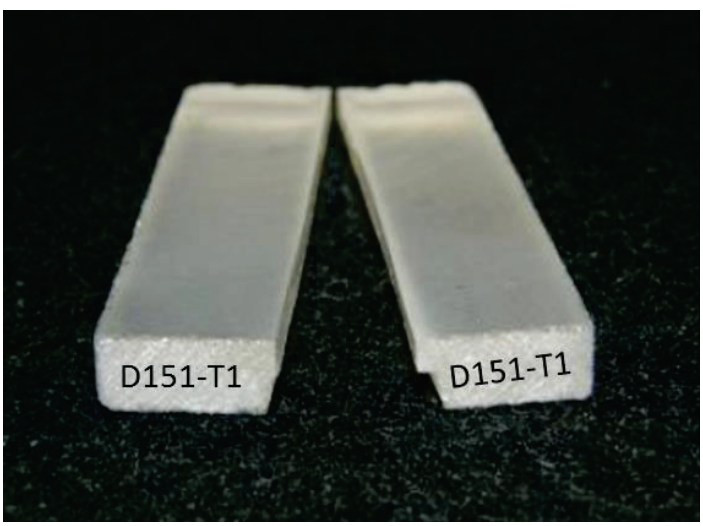

Figure 4. Photography illustrating a sample after breakage (with marking).

Table 1 summaries the machining conditions which were tested for each workpiece. The workpieces have been planeground on both sides primary with a fixed abrasive D151 grain size. The workpiece $\mathrm{n}^{\circ} 1$ has been removed after two passes of D151, the workpiece $n^{\circ} 2$ has been removed after two additional passes of D107, then the workpiece $n^{\circ} 3$ has been removed after 4 additional passes of D64. Finally, the workpiece $\mathrm{n}^{\circ} 4$ has been removed after 4 additional passes of D46.

Table 1. Parameter set up for the grinding of sphere surfaces.

\begin{tabular}{|l|c|c|c|c|}
\hline Workpiece $\mathrm{n}^{\circ}$ & 1 & 2 & 3 & 4 \\
\hline Diamond grain size & D151 & D107 & D64 & D46 \\
\hline Bond & Bronze & Bronze & Synthetic & Bronze \\
\hline & & & & \\
\hline Material removal rate $\left[\mathrm{mm}^{3} / \mathrm{s}\right]$ & 750 & 344 & 104 & 17 \\
\hline & & & & \\
\hline Sphere Radius [mm] & $\infty$ & $\infty$ & $\infty$ & $\infty$ \\
\hline Workpiece length[mm] & 350 & 350 & 350 & 350 \\
\hline workpiece width [mm] & 140 & 140 & 140 & 140 \\
\hline Number of samples (Radial + Axial) & 20 & 20 & 20 & 20 \\
\hline Number of pass D151 & 2 & 2 & 2 & 2 \\
\hline Number of pass D107 & 0 & 2 & 2 & 2 \\
\hline Number of pass D64 & 0 & 0 & 4 & 4 \\
\hline Number of pass D46 & 0 & 0 & 0 & 4 \\
\hline
\end{tabular}

The size of each block is $350 \times 160 \mathrm{~mm}$. The thickness of the blocks at the start of the sphere grinding was approximately $70 \mathrm{~mm}$. This large thickness ensures no very low vibrations during grinding process. After the grinding process, the sphere surfaces have been protected with a thin polymer film. The blocks then have been cut to a thickness of $5 \mathrm{~mm}$. The grooves of the backside also have been machined. Then the 20 samples have been separated and engraved. The process flow is shown Figure 5. 


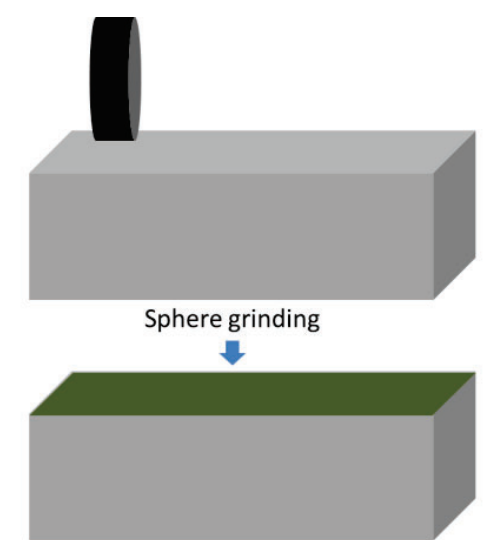

Protecting front surface

$\checkmark$

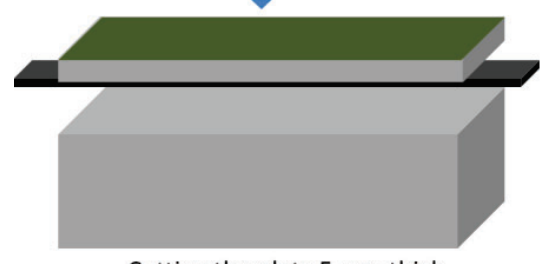

Cutting the plate $5 \mathrm{~mm}$ thick

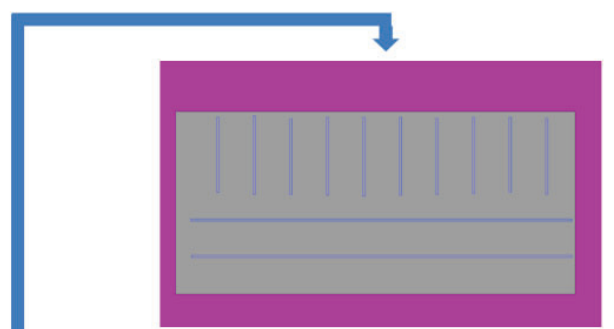

Grooves grinding on the backside $\checkmark$

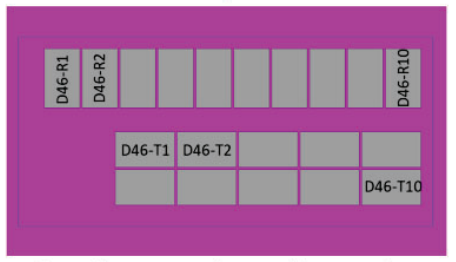

Samples separation and engraving

Figure 5. Process flow for the manufacturing of the samples.

\section{TEST PROCEDURE FOR SUBSURFACE DAMAGE ANALYSIS}

The test equipment for the analysis of the subsurface damage is conducted using a Leitz Ergolux microscope. The $\mathrm{x} 50$ objective has been used and both light sources have been used (incident light and transmitted light). The samples have been examined on the breaking edge (see Figure 6).

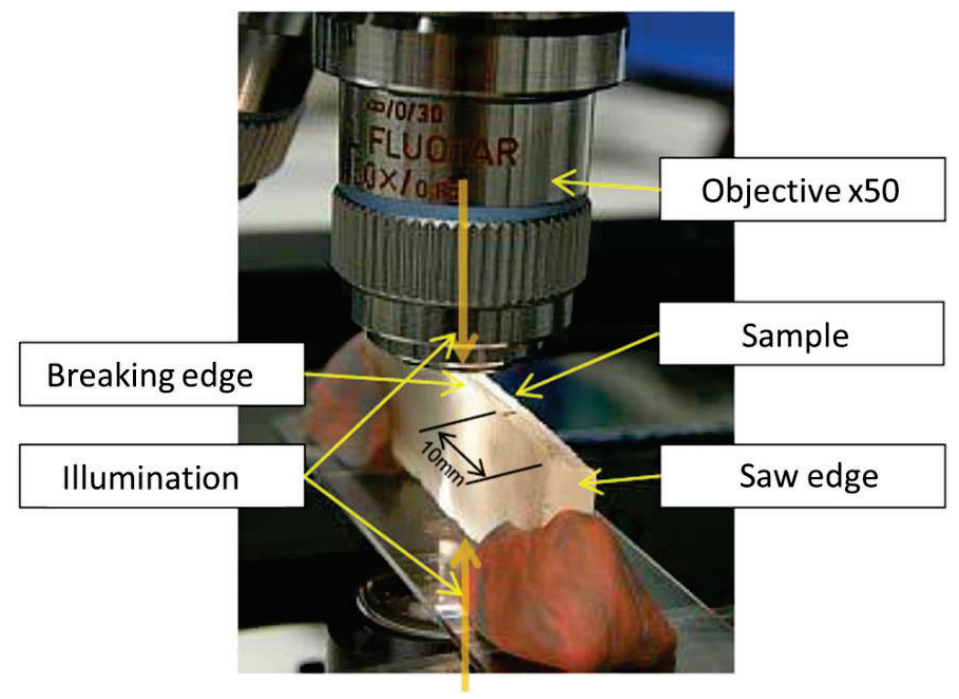

Figure 6. Microscope set-up for crack measurements. 
Four samples of D151 R, four samples of D64 R, and three samples of D46 R have been analyzed. A sample D151 T has additional examination to compare radial / tangential effects. An edge length of $30 \mathrm{~mm}$ has been investigated per sample. A length of $10 \mathrm{~mm}$ from each side has been excluded from measurement in order to avoid the influence from sawing operations on the cracks associated with separating the samples. The analysis of a sample includes the detection of the crack, measurement of the crack depth and the counting of the cracks. The crack depth is the distance between the observed crack and the sample surface (see Figure 7). It should be noted that the evaluation of the short cracks is limited due to the overlapping of the surface roughness. A distribution of crack depth has been evaluated: it is the number of cracks as they depend upon the crack's depth for each ground surface and the associated sequence of different grain sizes used.

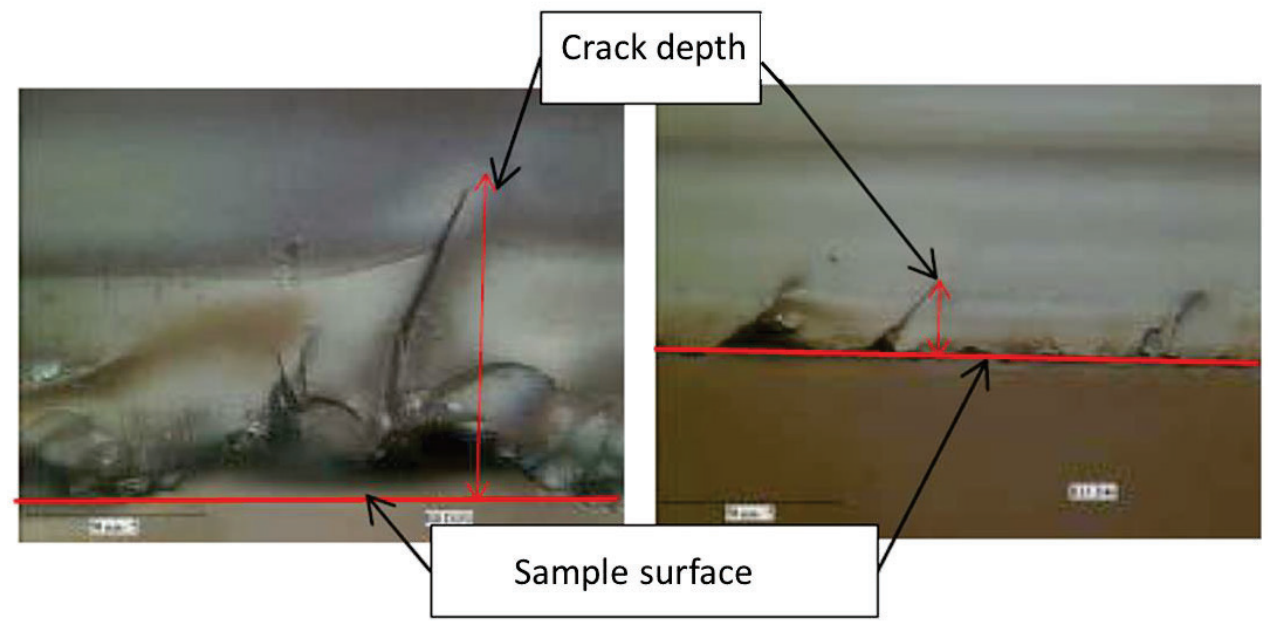

Figure 7. Crack depth measurement.

\section{RESULTS SUBSURFACE DAMAGE}

First, a comparison between a radial and tangential samples has been investigated. Both samples show a log-normal distribution and display quite similar values. That means there are no significant differences between the radial and tangential samples. For the following tests, both kinds of samples have been investigated. Figure 8 shows the fit of a lognormal distribution for the SSD for both tangential and radial D151 samples. Figure 9 shows the distributions of crack depths for each finished ground surfaces. The log-normal distribution provides an acceptable model for the distribution of the crack depth. A recapitulation of the crack depth distributions is shown Figure 10. It should be noted, that the distributions for D46 and D64 are very close to each other and overlapped. We have defined that the maximal SSD at the probability of $99.9 \%$ (see Figure 11). The cut off value of $99.9 \%$ has been chosen arbitrarily. The maximum SSD depths are 42, 35, 84 and $146 \mu \mathrm{m}$ for D46, D64, D107 and D151, respectively. Unexpectedly, the maximal SSD depth obtained for D64 is smaller than for D46. This is the result of the overlapping of both distribution functions. A possible reason for that is the different choices of process parameters for each grain size representing the standard manufacturing protocols at SCHOTT (as represented by different removal rate in Table 1) and also the different material of the tool bond (synthetic vs bronze). 

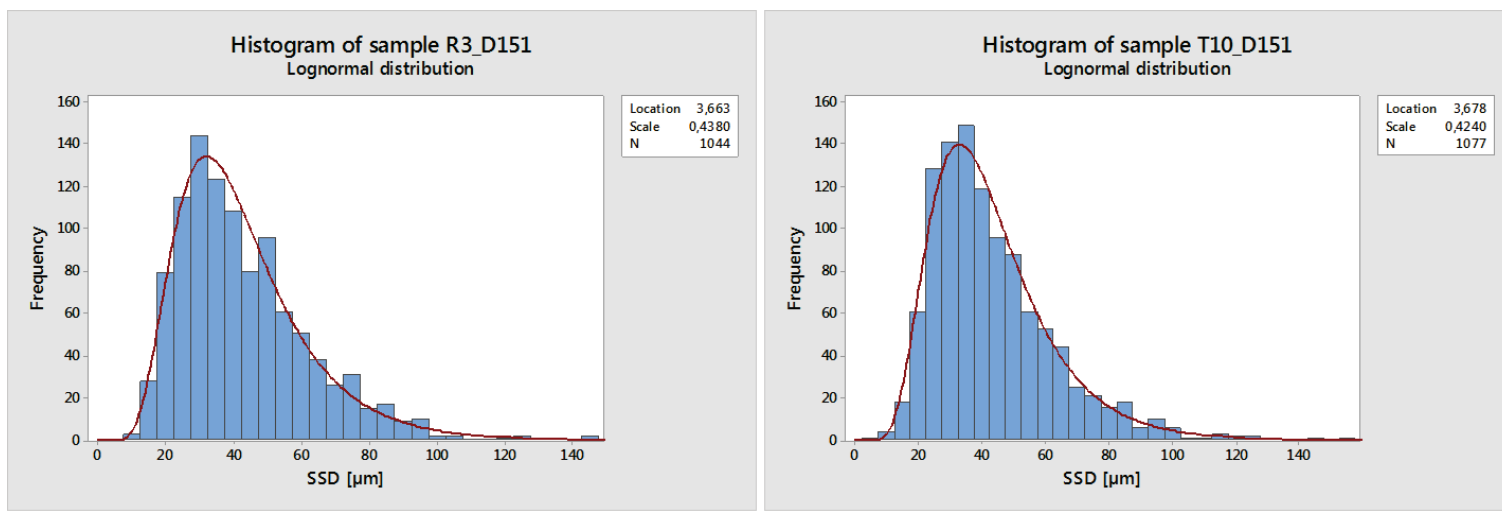

Figure 8. SSD distributions of radial and tangential sample, both are similar following a lognormal distribution.
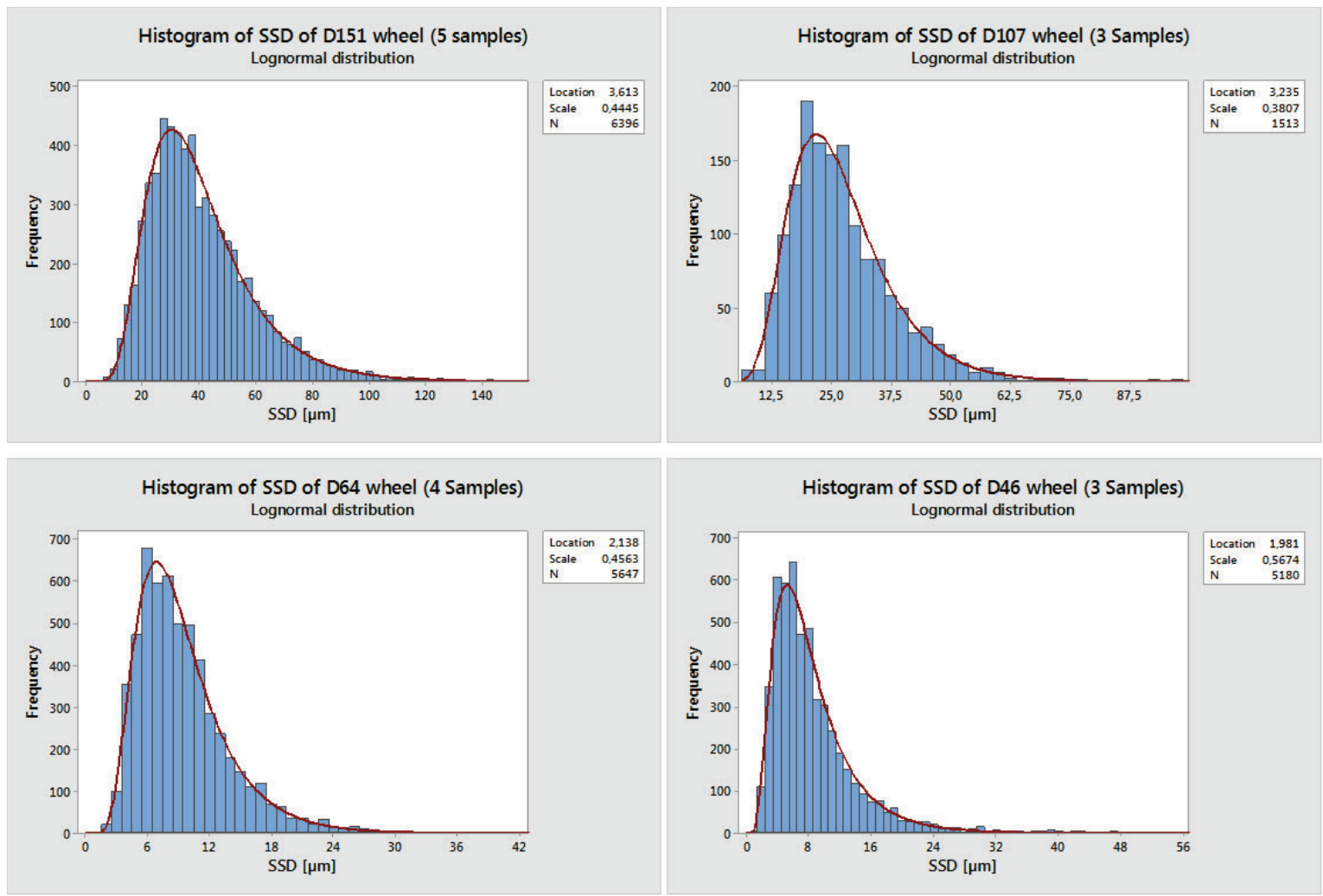

Figure 9. SSD distributions for each grain size ground surfaces. 


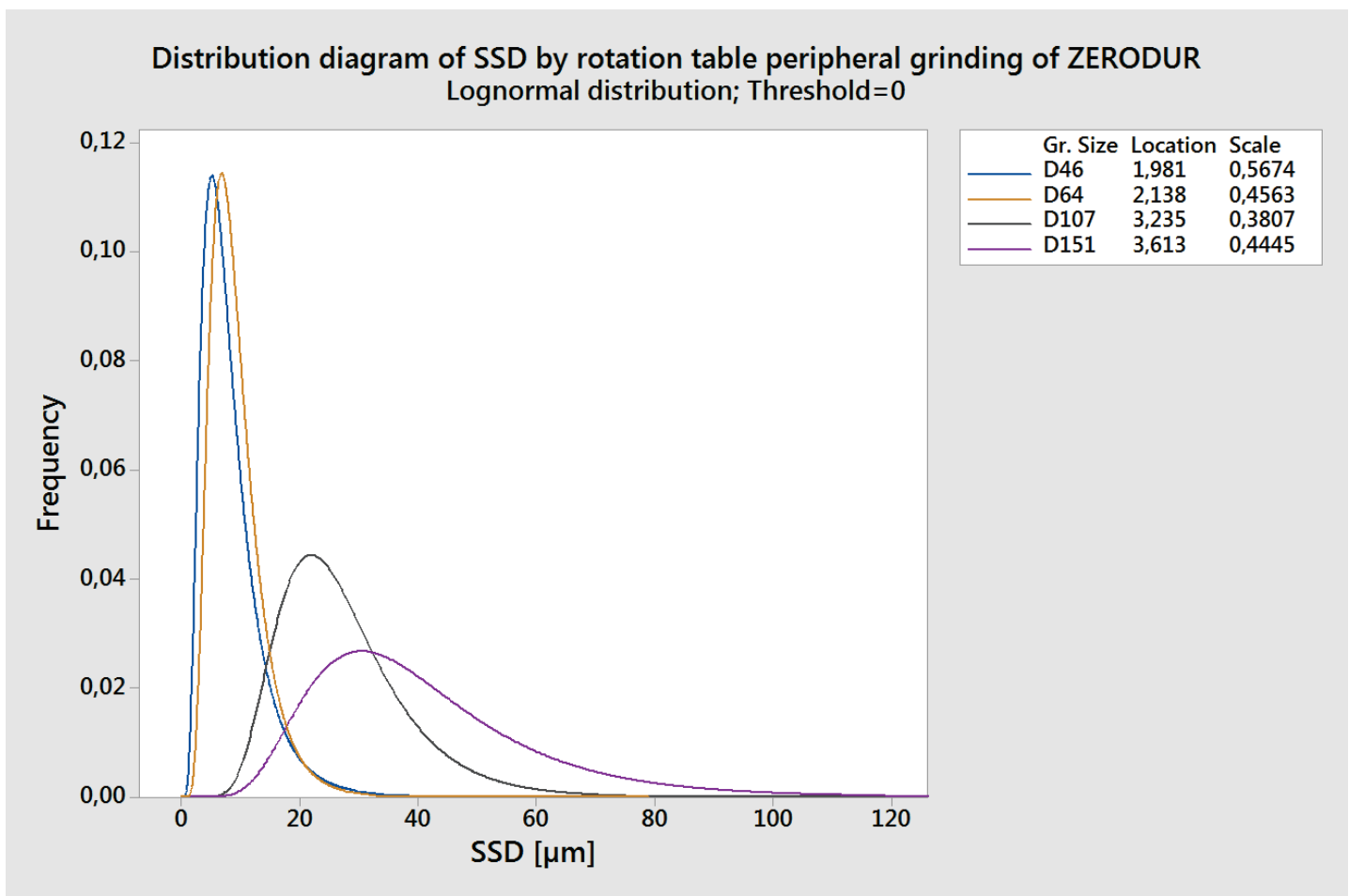

Figure 10. Summary of SSD distributions of ground surfaces from different grain sizes.

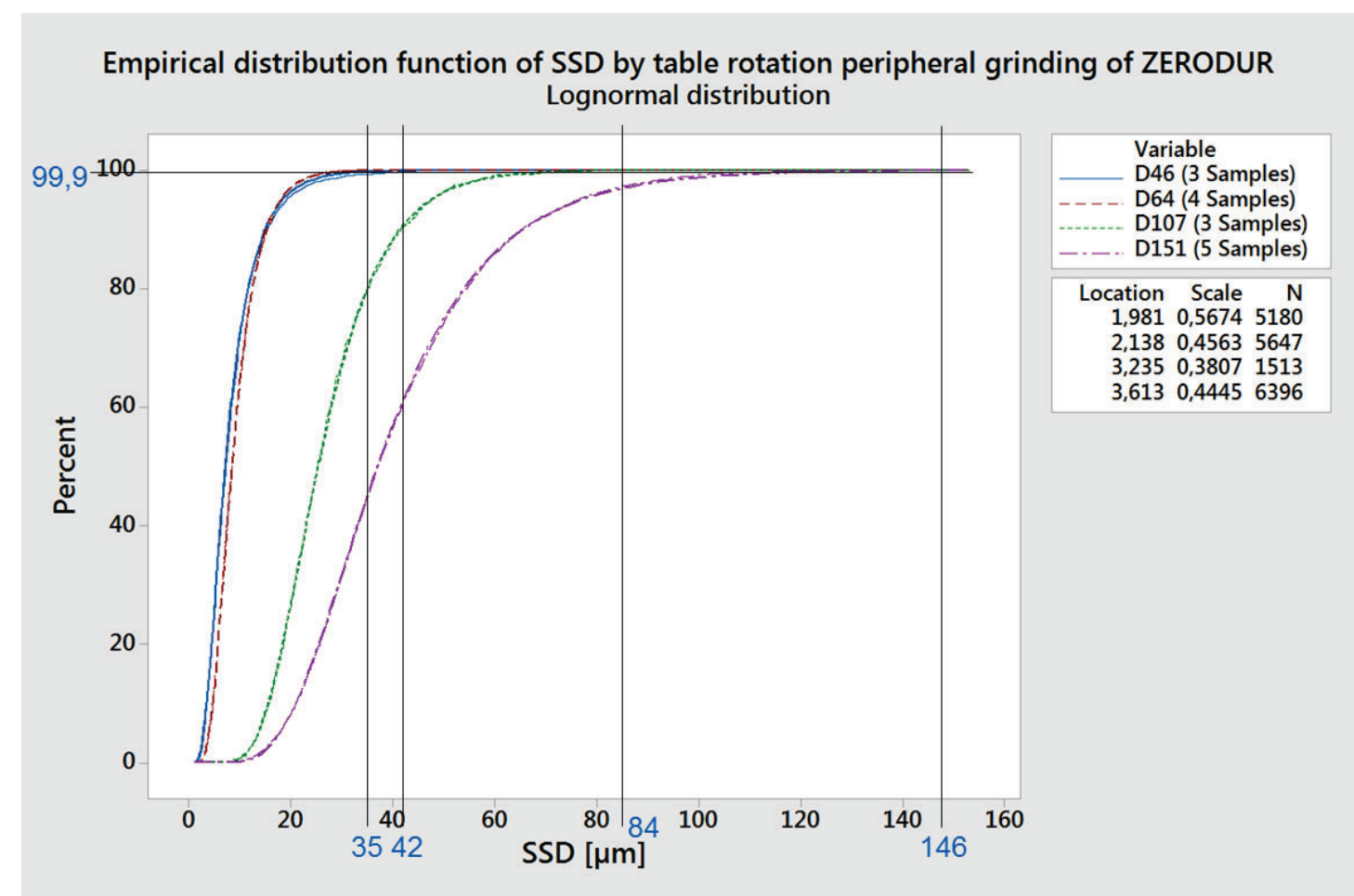

Figure 11. Empirical distribution functions of SSD of different abrasive grain size ground surfaces. 


\section{TEST PROCEDURE FOR SURFACE ROUGHNESS ANALYSIS}

The measurement of the surface roughness is by a Hommel Etamic W10 profilometer (Figure 12). The profilometer measures all common roughness variables according to international standards such as DIN EN ISO. Table 2 summarizes the parameters used for the measurements of the different finished ZERODUR ${ }^{\circledR}$ surfaces.

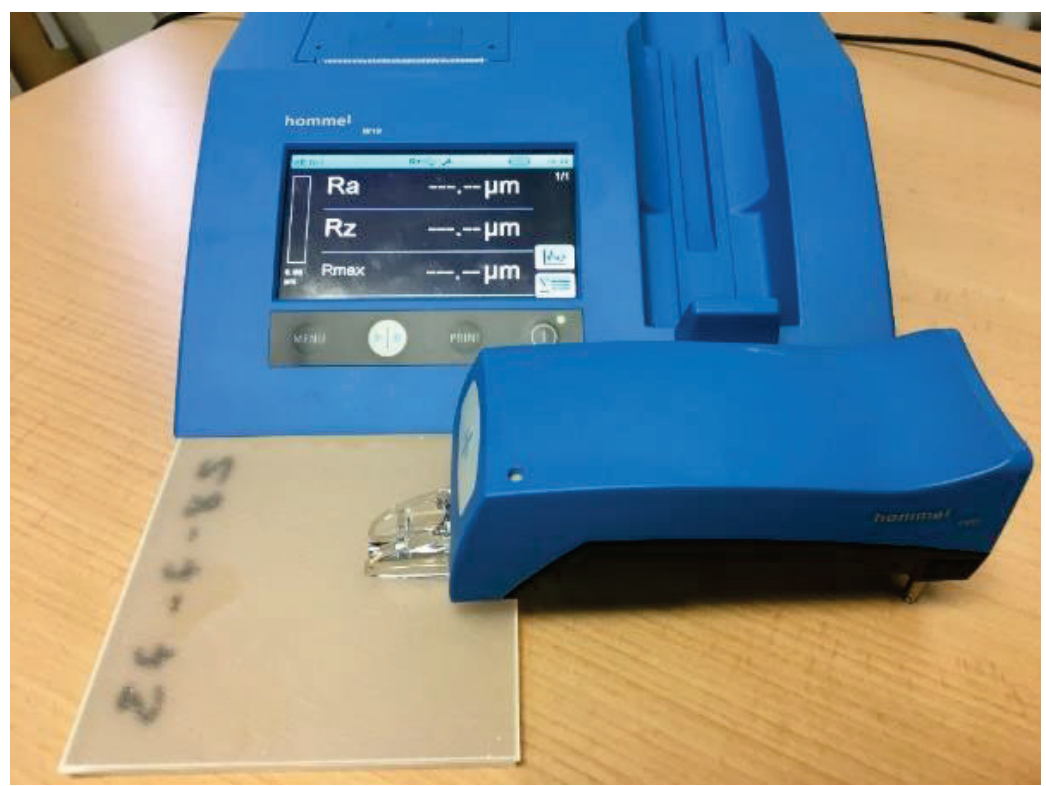

Figure 12. Profilometer Hommel Etamic W10 used for the SR measurements.

Table 2. Parameter set up for the SR measurements.

\begin{tabular}{|l|l|}
\hline \multicolumn{2}{|l|}{ Measurement parameter for D151 and D107 ground surfaces } \\
\hline Keying speed vt & $0,5 \mathrm{~mm} / \mathrm{s}$ \\
\hline Traversing & $15 \mathrm{~mm}$ \\
\hline Data point spacing & $1,6 \mu \mathrm{m}$ \\
\hline Measuring range & $160 \mu \mathrm{m}$ \\
\hline Roughness button & T1E \\
\hline Profilometer & W10 \\
\hline
\end{tabular}

\begin{tabular}{|l|l|}
\hline \multicolumn{2}{|l|}{ Measurement parameter for D64 and D46 ground surfaces } \\
\hline Keying speed vt & $0,5 \mathrm{~mm} / \mathrm{s}$ \\
\hline Traversing & $4,8 \mathrm{~mm}$ \\
\hline Data point spacing & $0,5 \mu \mathrm{m}$ \\
\hline Measuring range & $80 \mu \mathrm{m}$ \\
\hline Roughness button & $\mathrm{T} 1 \mathrm{E}$ \\
\hline Profilometer & $\mathrm{W} 10$ \\
\hline
\end{tabular}

\begin{tabular}{|l|l|}
\hline \multicolumn{2}{|l|}{ Conditions of analysis for D151 and D107 ground surfaces } \\
\hline$\lambda s$ & $8 \mu \mathrm{m}$ (Auto) \\
\hline$\lambda c$ & $2,5 \mathrm{~mm}$ \\
\hline$\lambda f$ & off \\
\hline Filter ISO 4287 & ISO11562 \\
\hline Filter ISO 13565 & ISO 13565-1 \\
\hline Orientation & on \\
\hline Form removal & off \\
\hline
\end{tabular}

\begin{tabular}{|l|l|}
\hline \multicolumn{2}{|l|}{ Conditions of analysis for D64 and D46 ground surfaces } \\
\hline$\lambda s$ & $8 \mu \mathrm{m}$ (Auto) \\
\hline$\lambda c$ & $0,8 \mathrm{~mm}$ \\
\hline$\lambda f$ & off \\
\hline Filter ISO 4287 & ISO11562 \\
\hline Filter ISO 13565 & ISO 13565-1 \\
\hline Orientation & on \\
\hline Form removal & off \\
\hline
\end{tabular}

15 measurements have been performed on one sample for each of the ground surfaces. Figure 13 shows the position of each measurement. The measurements 1 till 5 have been at an orientation of the profilometer of $0^{\circ}$, the measurements 5 till 10 have been at an orientation of $45^{\circ}$ and finally the measurement 10 till 15 have been at an orientation of $90^{\circ}$. 


\section{Surface approx. $50 \times 50 \mathrm{~mm}$}

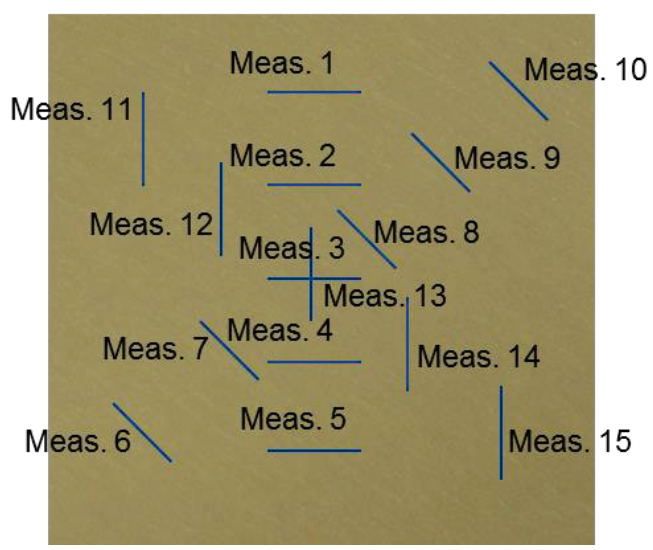

Figure 13. Position of the 15 measurement for each ground surface

\section{RESULTS SURFACE ROUGHNESS}

Figure 14 shows examples of as-measured SR profiles. For each ground surface measurement 1 is displayed. The standard surface roughness profile parameters have been analysed and summarized in Figure 15. As excepted the roughness is decreasing with smaller grain sizes. Figure 16 shows the empirical function of distribution for all 15 roughness profiles measured for each grain size. We find that the roughness profiles data do not fit well a normal distribution especially diverging for small grain size. The same is true for the profiles measured in the same orientations. For this reason a large amount of measurements have to be done to characterize the surface topography properly. The normal distribution provides an acceptable model for the distribution of the roughness profile, at least for a minimum of 15 measurements on different orientations. Figure 17 shows the distribution function of the concatenation of the 15 surface roughness profiles for each grain size (blue line). The data can be fitted very well to a normal distribution indicated in bold red line. We believe the standard deviation of the model of the normal distribution is a good indicator for characterization of the SR. It will be used later for the correlation between SSD, SR and grain size of the abrasive. Figure 18 shows histogram of the surface roughness profile for each finished ground surfaces. Additionally, the roughness of a typical ground surface with D20 tool and SCHOTT standard parameters has been measured and analyzed. A normal distribution could be fitted to all histogram (red line) and the standard deviation was determined. Again, the larger the grain size, the better the fit. A recapitulation of the SR profile distributions is shown Figure 19. The calculated empirical distribution functions of roughness profile on different grain size ground surfaces are summarized Figure 20. 

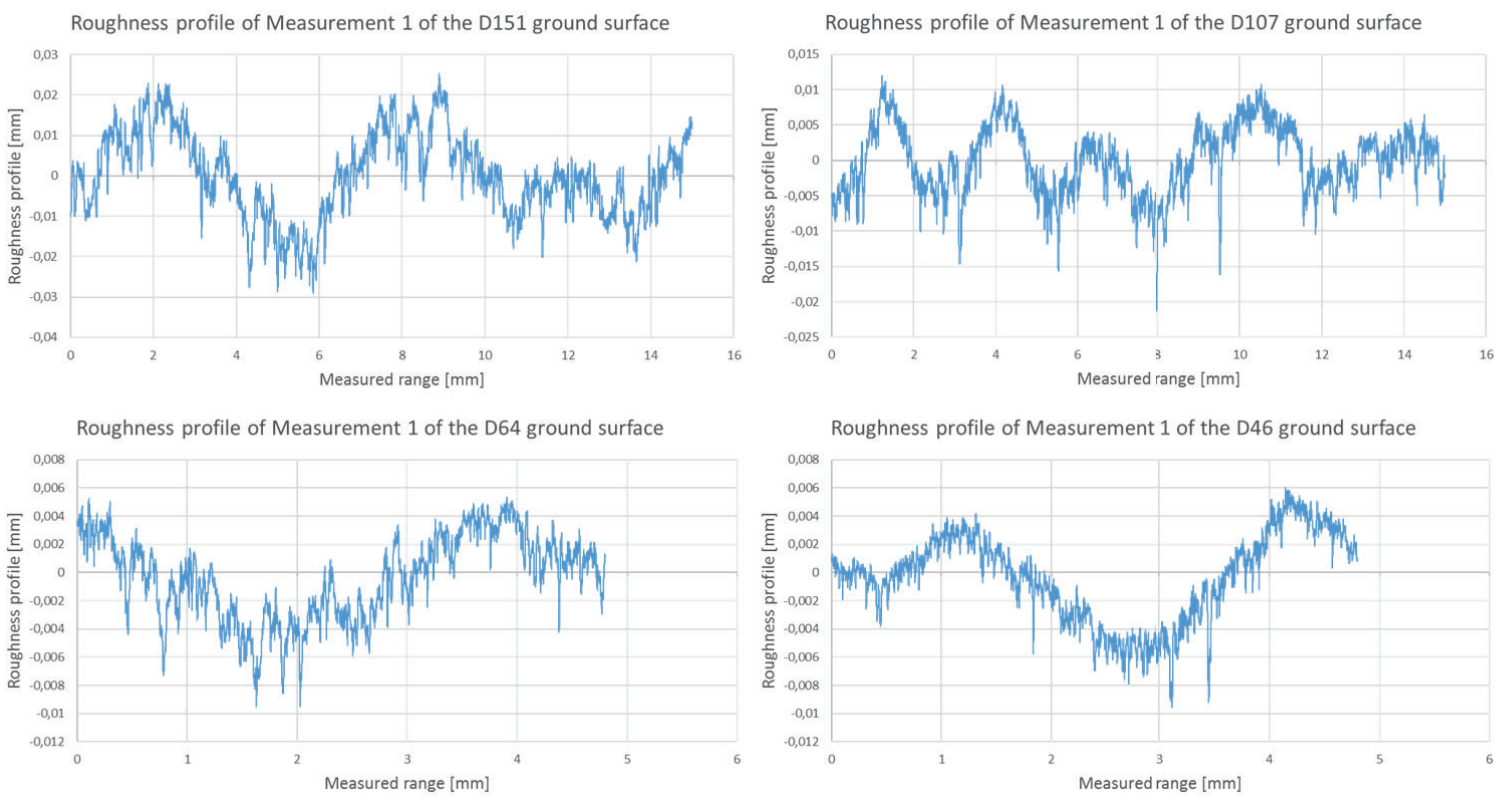

Figure 14. Surface roughness profile of each grain size ground surfaces.
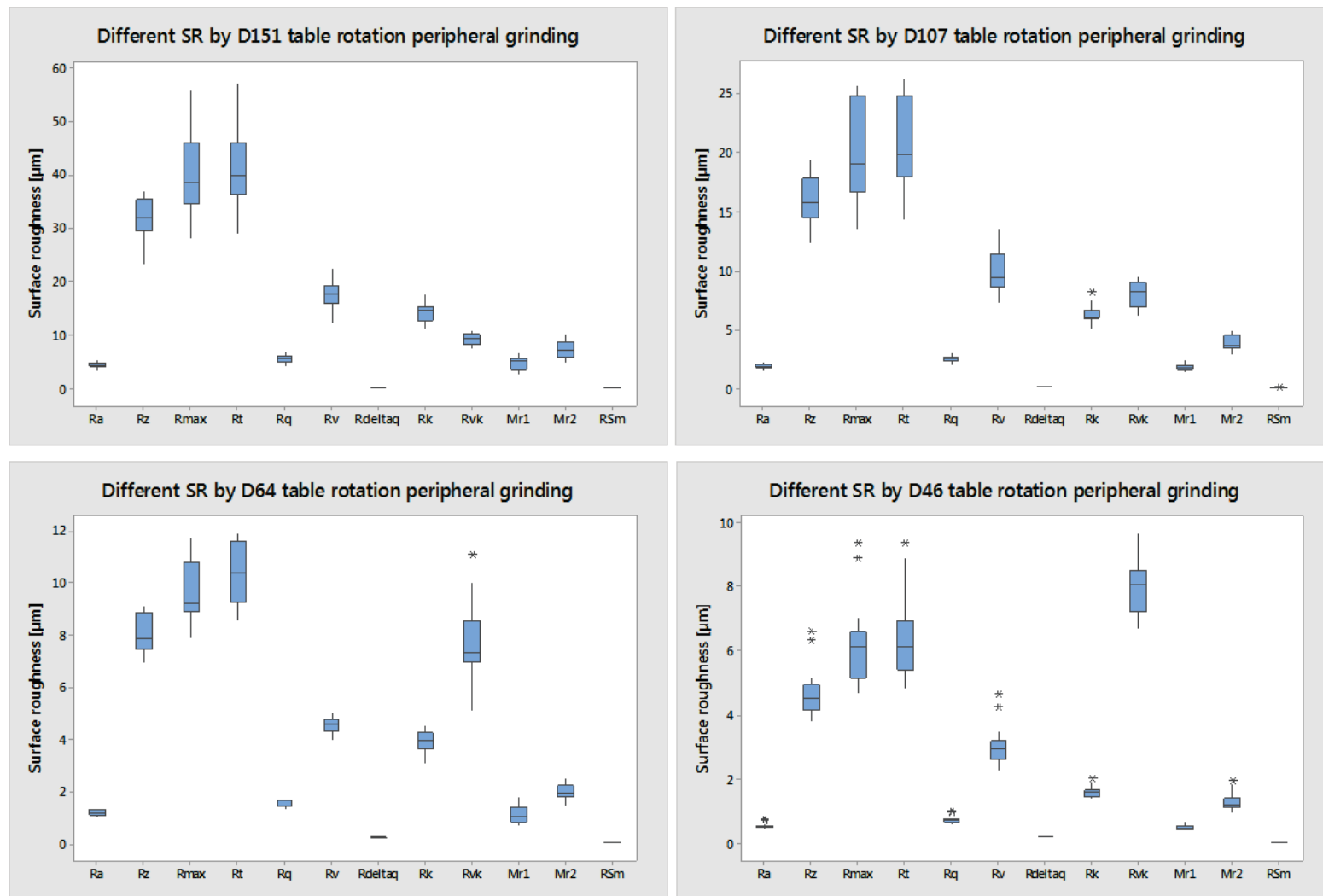

Figure 15. Summary of SR evaluated by standard profile roughness parameters for each grain size ground surfaces. 

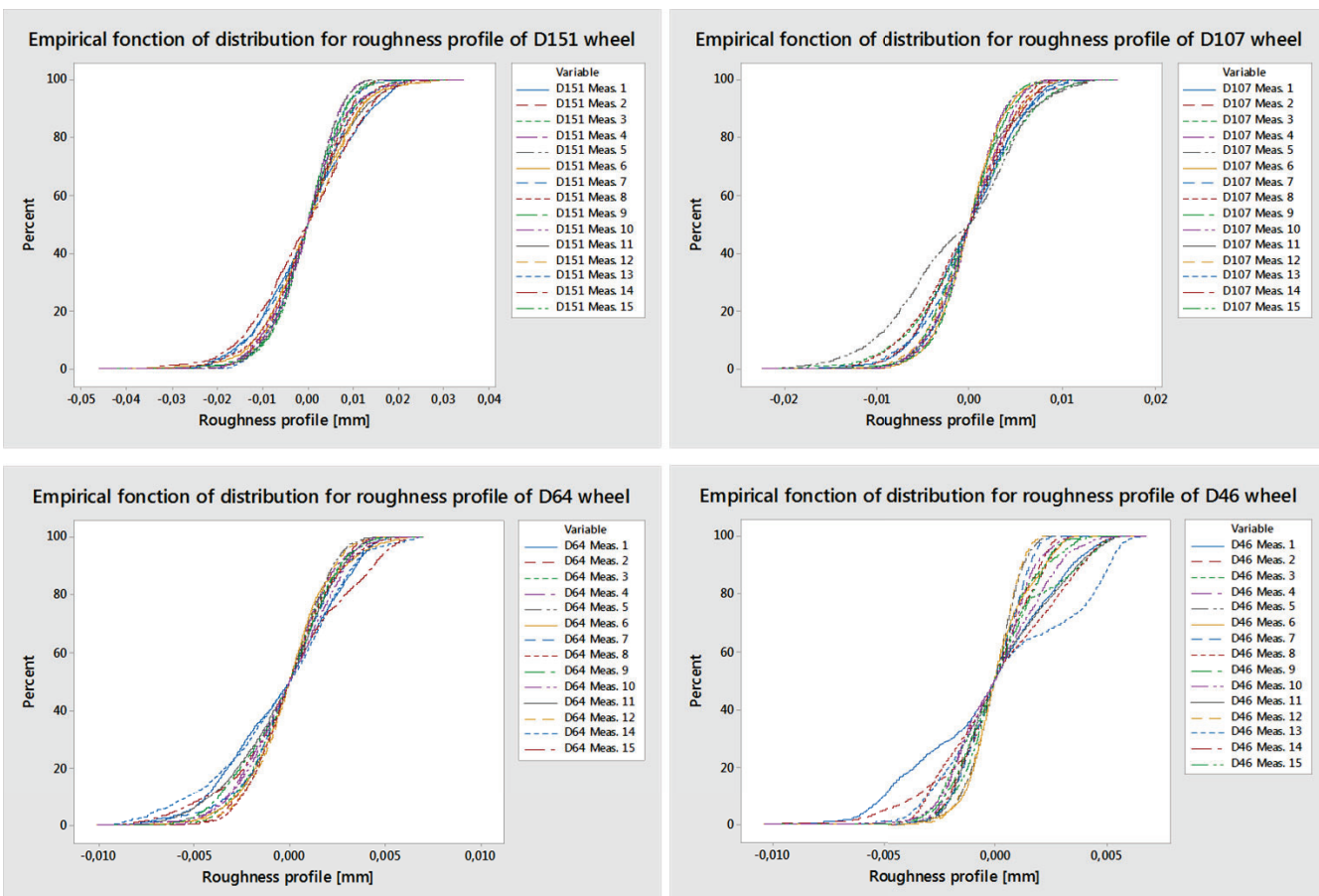

Figure 16. Empirical functions of distribution of surface roughness profile of different grain size ground surfaces for each measurement.
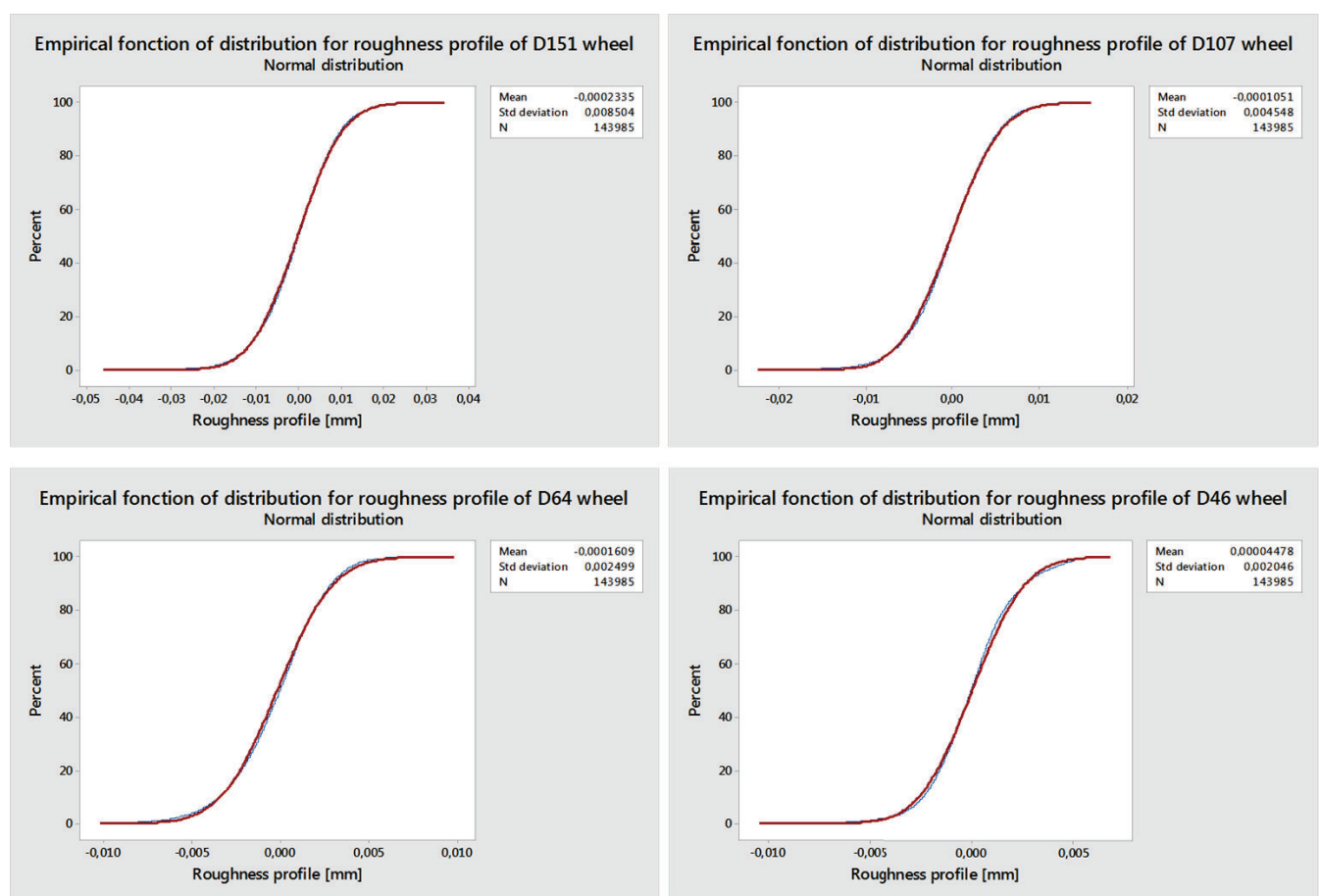

Figure 17. Empirical functions of distribution of surface roughness profile of different grain size ground surfaces (15 measurements concatenated in blue and fitted normal distribution in red). 

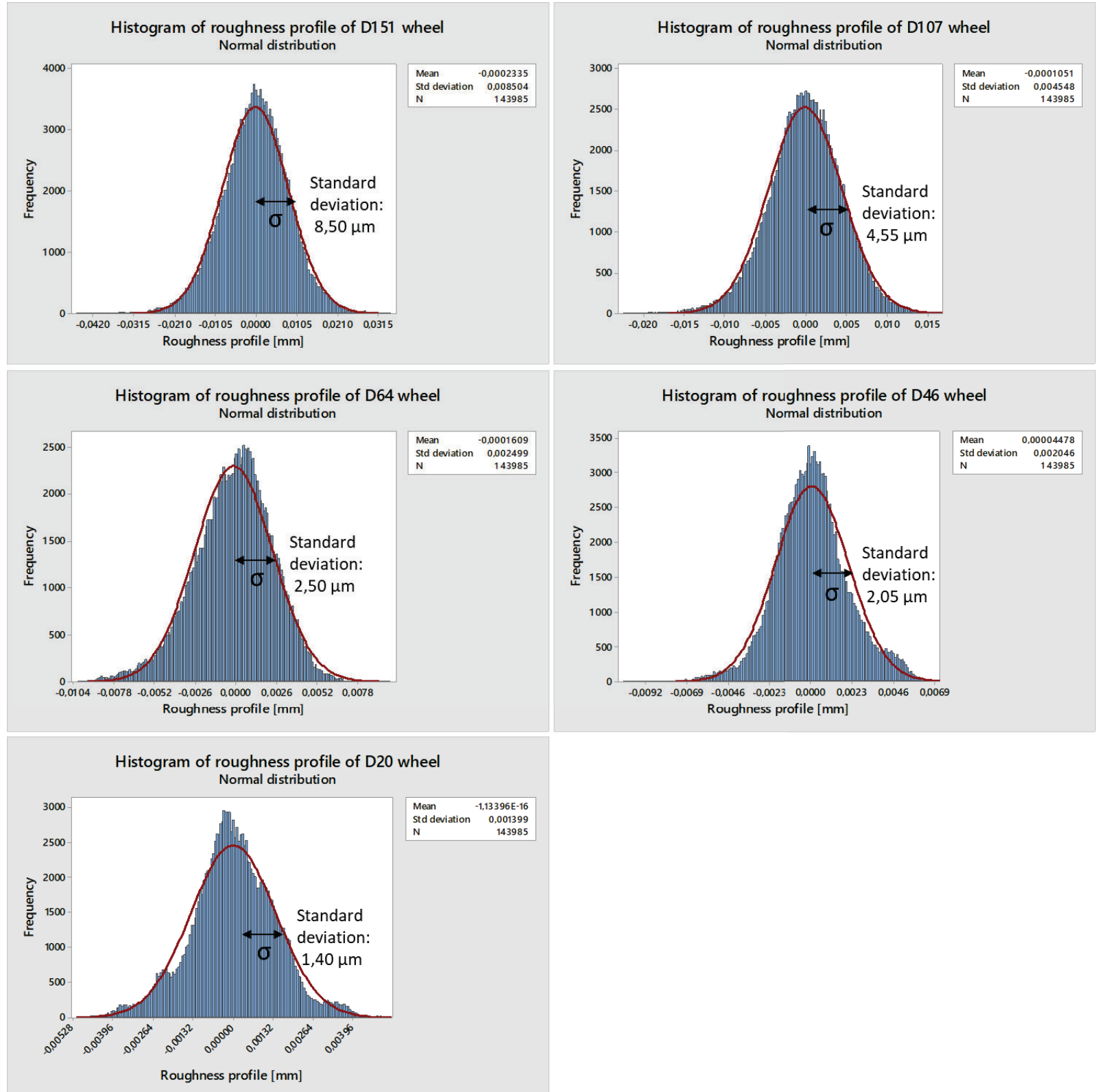

Figure 18. Surface roughness profile distribution for each grain size ground surfaces. 


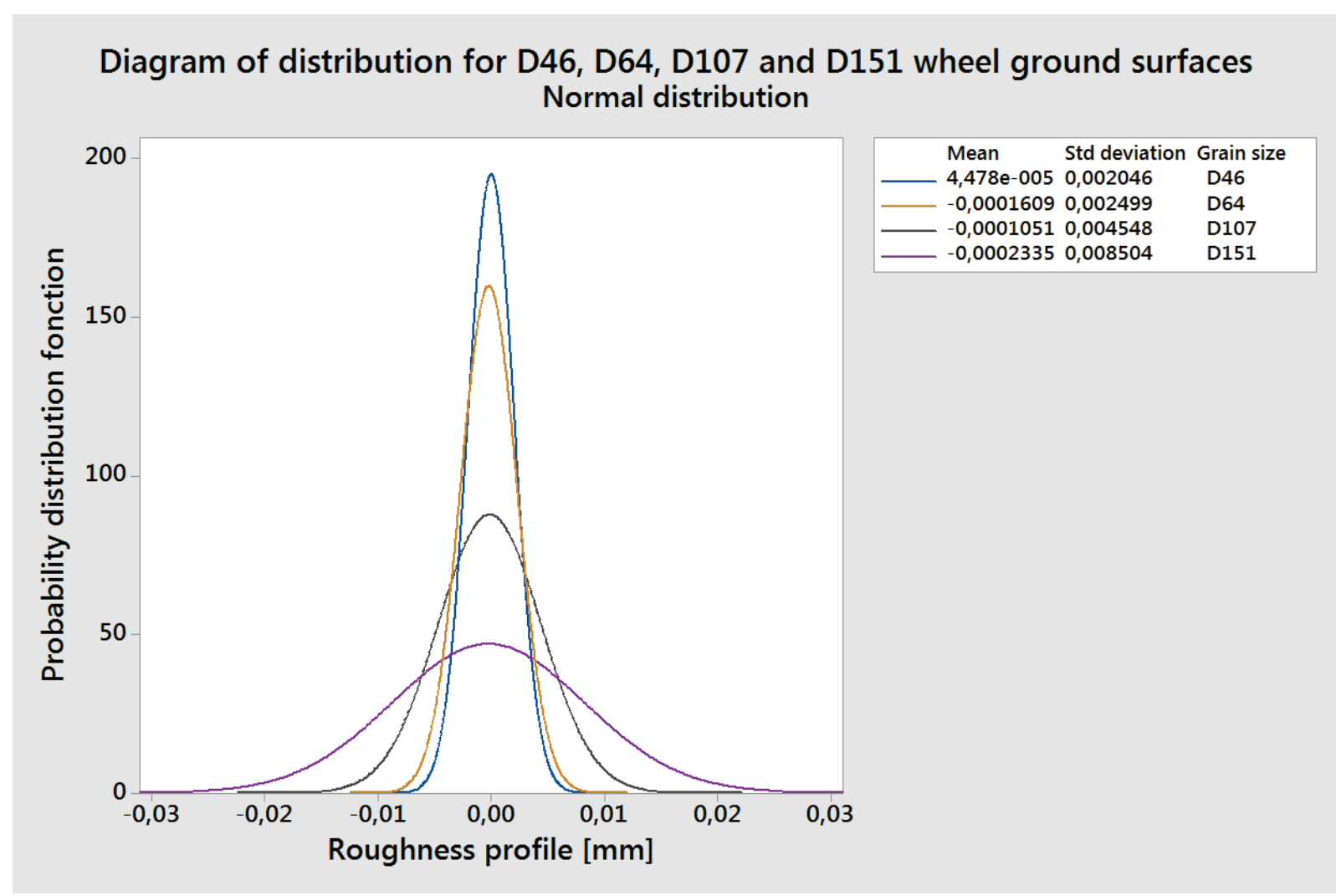

Figure 19. Summary of the distributions of surface roughness profile of different grain size ground surfaces. 


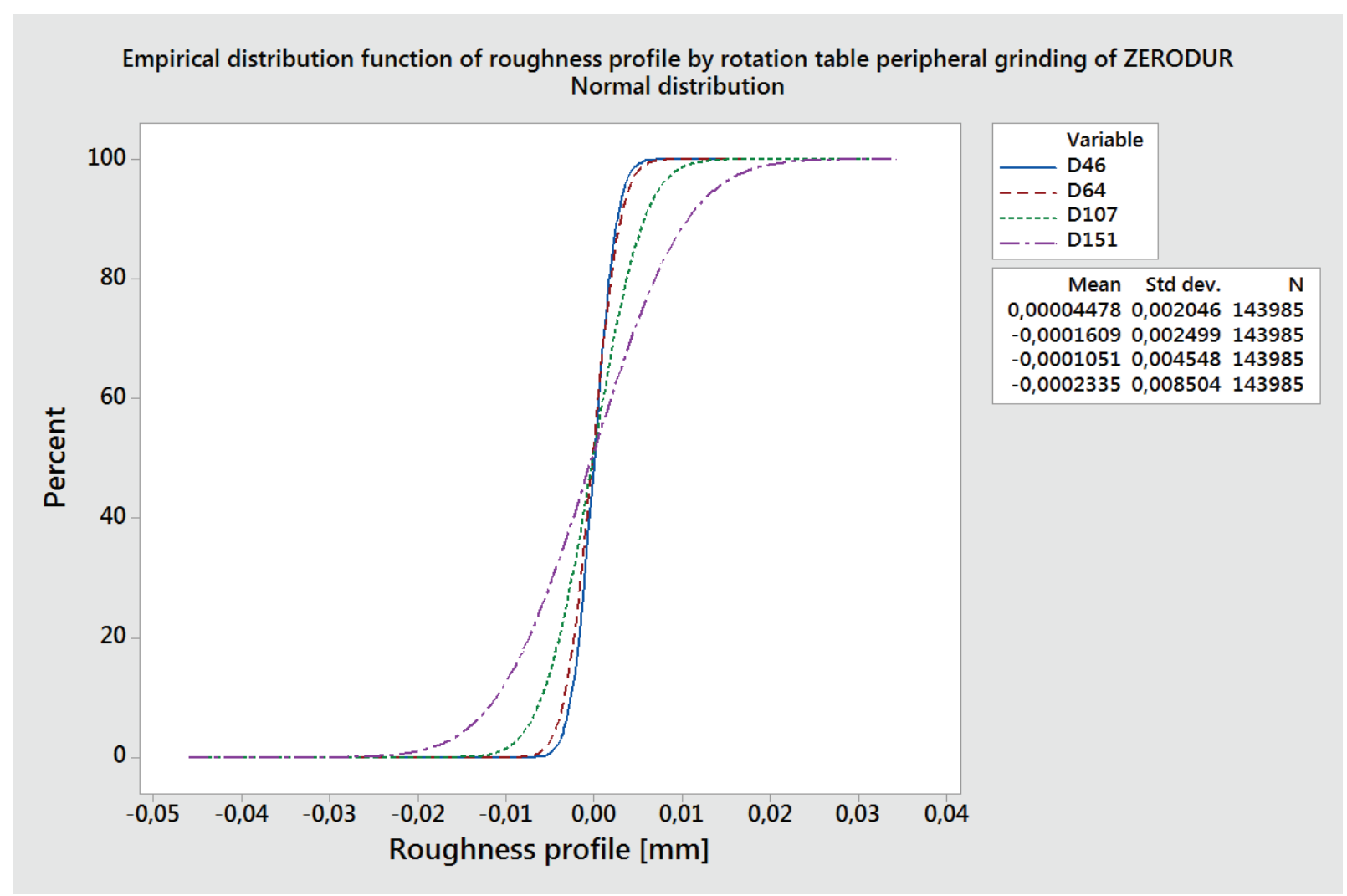

Figure 20. Empirical distribution functions of roughness profile of different grain size ground surfaces.

\section{CORRELATION BETWEEN SUBSURFACE DAMAGE AND SURFACE ROUGHNESS}

Based on an extensive analysis involving a variety of optical glasses, abrasive sizes and grinding processes, including those using loose abrasives, ring tools, pellets, wheels, and saws, Lambropoulos[2] has suggested that the depth of SSD (in $\mu \mathrm{m}$ ) resulting from abrasive processes lies within the bounds given by the expression:

$$
0.3 \mathrm{~d}^{0.68}<\operatorname{SSD}(\mu \mathrm{m})<2 \mathrm{~d}^{0.85}
$$

where $\mathrm{d}$ is the size, in $\mu \mathrm{m}$, of the abrasive used during the grinding operation. Correlations have also been proposed that relate the depth of subsurface damage to the roughness of the resultant surface.

Later, Alenikov[3] reported that the ratio of the SSD depth to the surface roughness was $3.93 \pm 0.17$ for a series of glasses and ceramics which had been ground using a range of loose SiC abrasives. In the late 1980s, Paul Hed[4] and coworkers extended Alenikov's work by studying the relationship between surface roughness and SSD for three optical glasses (BK7, 7940 fused silica and ZERODUR ${ }^{\circledR}$ ) that had been ground using both fixed diamond and boron carbide abrasives. They found a ratio between SSD depth and peak-to-valley surface roughness (as measured by surface profilometry) that was significantly higher $(6.4 \pm 1.3)$ than those reported in previous studies. A considerably lower ratio has been reported by Lambropoulos [5] et al. who report a ratio of less than two. Suratwala [6] has investigated SSD depth on fused silica and he found a correlation between max SSD depth and roughness of 49. The differences in the ratio reported by these workers are likely due to the differences in the methodologies used to estimate roughness and SSD depth [7], as well as various kind of the grinding processes and ground material. The surface roughness Rz (Figure 15) and the maximal subsurface damage has been measured for the 4 different ground surfaces D151, D107, D64 and D46 (Figure 11) and the ratio SSD / SR has been calculated (see Table 3). There is no obvious linear correlation between SSD and Rz values with respect to 
different grain sizes. Beside the Rz parameter, all others standard roughness profile parameters have been tested and no correlation has been found.

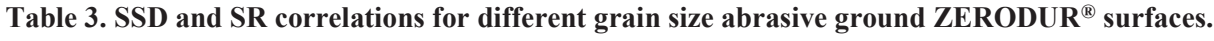

\begin{tabular}{|c|c|c|c|}
\hline & Max. SSD $(99,9 \%)[\mu \mathrm{m}]$ & SR Rz $[\mu \mathrm{m}]$ & Max. SSD / SR \\
\hline D46 & 41,9 & 4,7 & 8,9 \\
\hline D64 & 34,7 & 8,1 & 4,3 \\
\hline D107 & 83,9 & 15,9 & 5,3 \\
\hline D151 & 146,4 & 31,7 & 4,6 \\
\hline
\end{tabular}

On the other hand looking at the roughness profile the standard deviation can be identified as a measure for the surface roughness as shown Figure 21. Linear correlations between standard deviation of the roughness profile (SR), maximum SSD and nominal mesh size of abrasive have been found (see Figure 22 till Figure 24). The ratio max. SSD / roughness profile standard deviation is 17.4 obtained by a linear fit through the origin. The orange point on Figure 22 shows the measured SR of machined surface with D20 tool. The SSD has not been yet analyzed. Therefore the max. SSD is an extrapolation of the linear fit, which gives a value of about $24 \mu \mathrm{m}$. the ratio of the maximum SSD to nominal mesh size of abrasive amounts to 0,88 while the SR profile standard deviation vs nominal mesh size of tool abrasive is 0,05 . These linear correlations allow to estimate the maximum SSD depth by measuring the SR with a profilometer. Furthermore, the SSD can be also predicted from the nominal mesh size of tool abrasive by using SCHOTT standard process parameters.

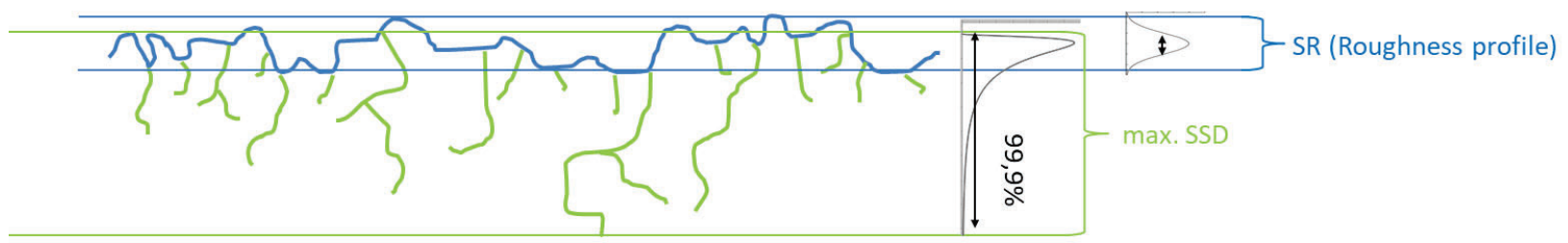

Max. SSD $(99,9 \%)=17,4 \times$ roughness profile standard deviation

Figure 21. Sketch of surface roughness and subsurface damage depth profiles. 


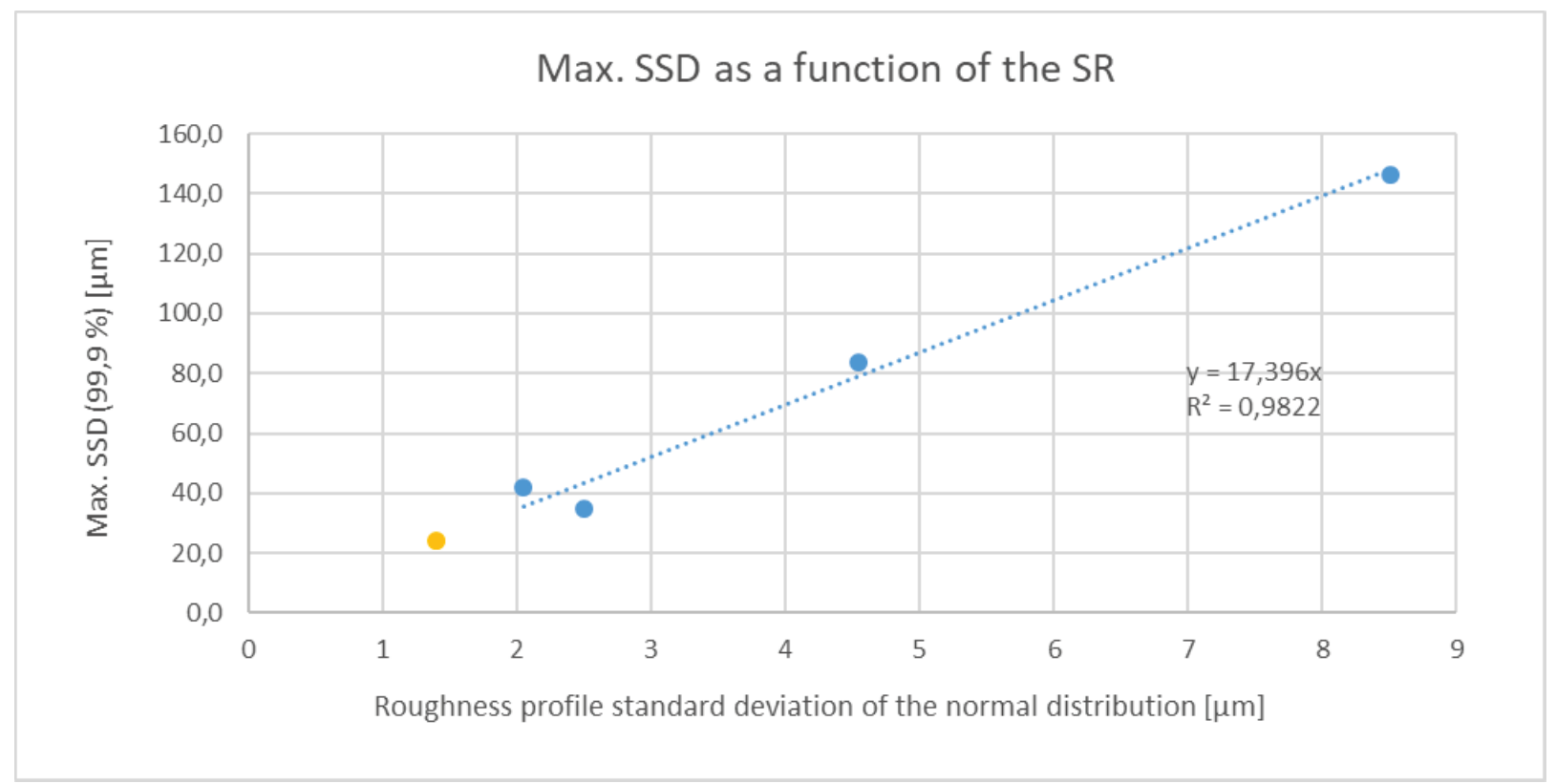

Figure 22. Correlation between max. SSD depth and SR.

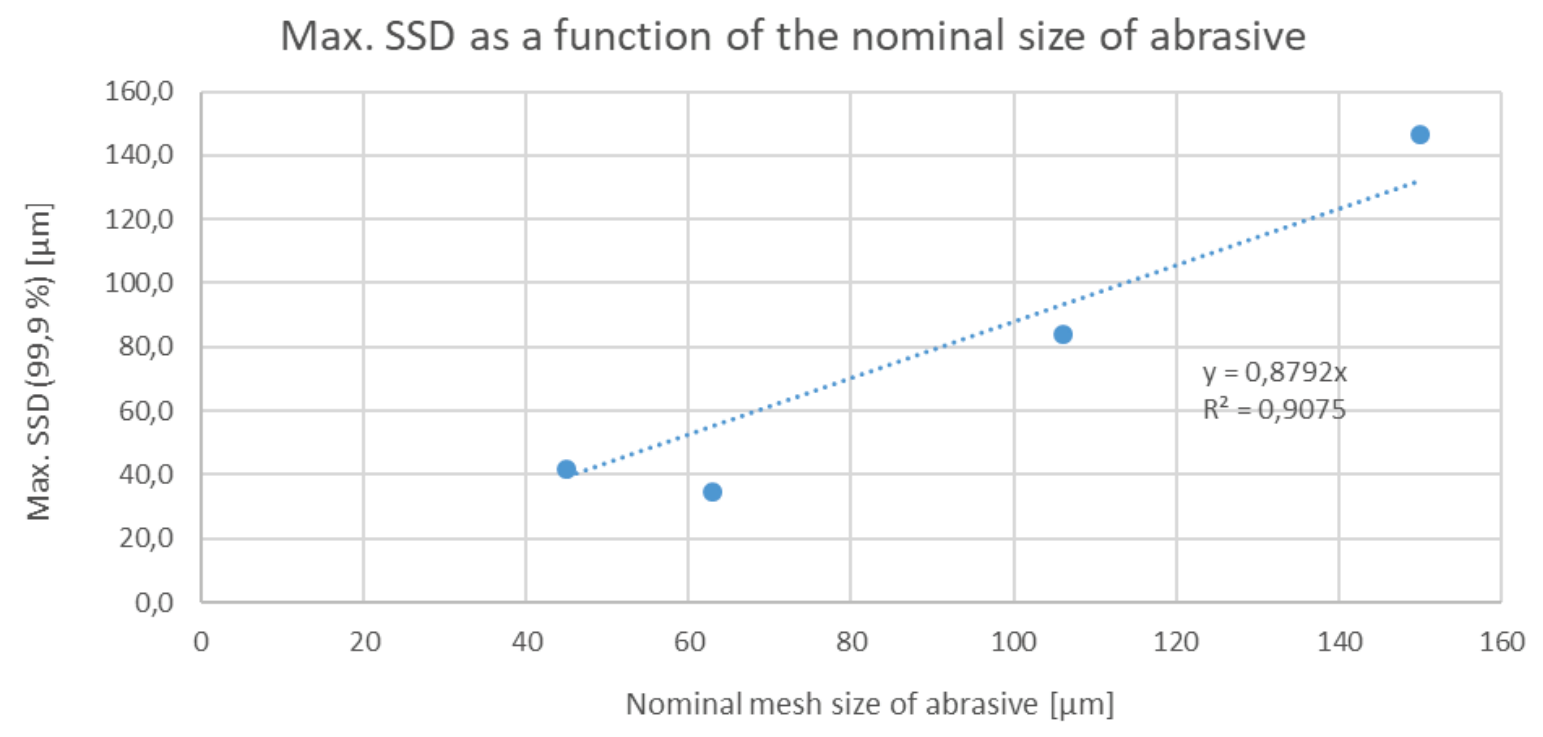

Figure 23. Correlation between max. SSD depth and nominal mesh size of tool abrasive. 


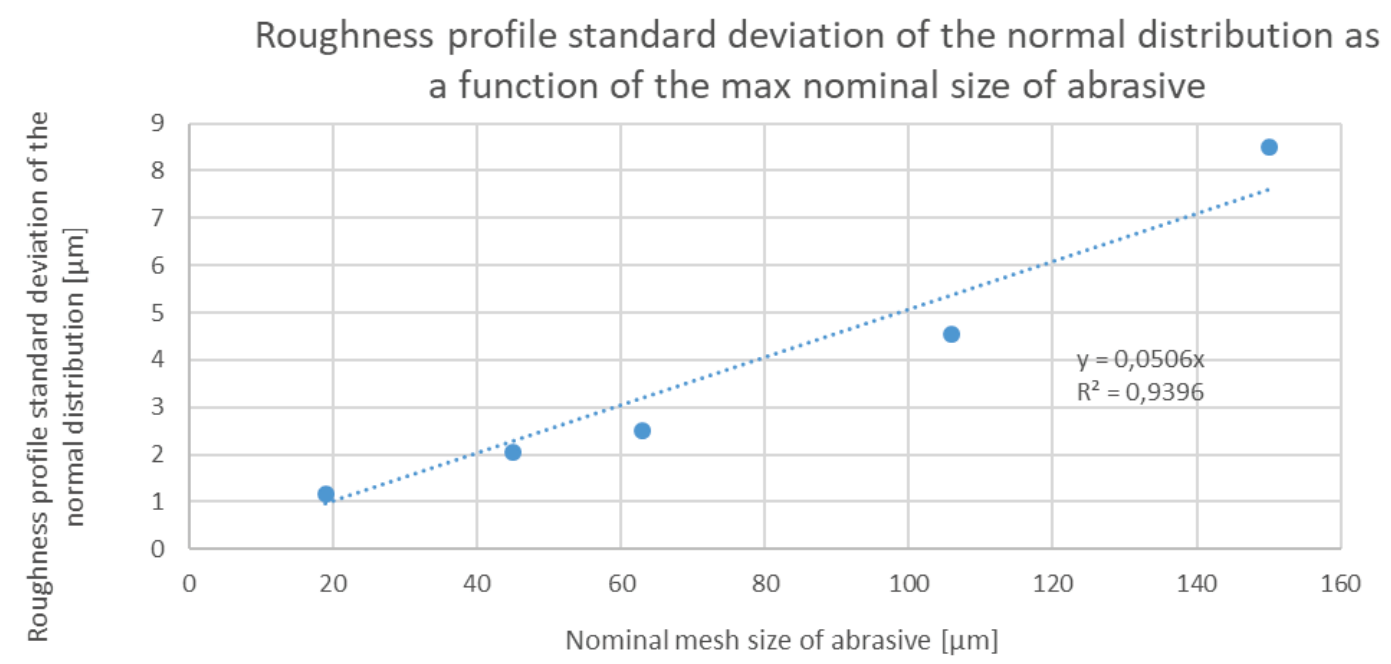

Figure 24. Correlation between SR and nominal mesh size of tool abrasive.

\section{SUMMARY}

The SSD and SR have been measured and statistically evaluated for the rotation table peripheral grinding. This method of grinding is the standard rough and fine grinding process for mirror surface shaping at SCHOTT. The SSD depth distributions are typically described by a log-normal distribution and the SR distributions are described by a normal distribution. The maximum SSD of ground ZERODUR ${ }^{\circledR}$ sphere or asphere by rotation table peripheral grinding with D46, D64, D107 and D151 tool grain size is respectively 42, 35, 84 and $146 \mu \mathrm{m}$. Lambropoulos expression $\left(0.3 \mathrm{~d}^{0.68}<\mathrm{SSD}(\mu \mathrm{m})\right.$ $<2 \mathrm{~d}^{0.85}$ ) is valid for the present experiment, nevertheless the ratio SSD / SR does not give a constant value for the four diamond grain sizes. A relationship between SSD and SR has been found, which allows with this grinding process to estimate the maximum SSD depth by measuring the SR with a profilometer. This ratio max. SSD / Roughness profile standard deviation is 17.4. It would be interesting in future work to analyze the SSD distribution on a D20 surface and to check if the SSD, SR and nominal abrasive size parameters are matching the current correlations. This represents an analytic tool that should be effective, in conjunction with accurate milling of the mirror's optical surface, to significantly accelerate the time and effort needed in optical fabrication and lowering the risk and costs to produce an optical surface. In the case of lightweight mirrors, having milled an accurate profile with comparable low levels of SSD means that the optical fabricator does not need to first induce quilting via large tools and pressures otherwise necessary to realize the aspheric shape while removing the SSD layer. Significant net savings of effort are entirely feasible.

\section{ACKNOWLEDGEMENTS}

We would like to thank:

- Irmgard W. and Inge B., department "Reliability and Lifetime" of SCHOTT AG for the support in the analysis of the samples; 


\section{REFERENCES}

[1] -[7] P.E. Miller, T.I. Suratwala, L.L. Wong, M.D. Feit, J.A. Menapace, P.J. Davis and R.A. Steele, "The Distribution of Subsurface Damage in Fused Silica”, University of California, Lawrence Livermore National Laboratory, P.O. Box 808, Livermore, CA 94550

[2] J.C. Lambropoulos, "From Abrasive Size to Subsurface Damage in Grinding” OSA Technical Digest (Optical Society of America, Washington D.C., 2000), pp. 17-18

[3] F.K. Aleinikov, "The Effect of Certain Physical and Mechanical Properties on the Grinding of Brittle Materials" in Sov. Phys. Tech. Phys. 27,2529-2538 (1957)

[4] D.F. Edwards and P.P. Hed "Optical Glass Fabrication Technology II: The Relationship Between Surface Roughness and Subsurface Damage” Appl. Optics 26, 4677-4680 (1987)

[5] J.C. Lambropoulos, Y. Li, P.D. Funkenbusch, and J. Ruckman "Non-contact Estimate of Grinding Induced Subsurface Damage" in Optical Instrumentation and Testing III, H.P. Stahl, ed., SPIE Proc.3782, 41-50 (1999)

[6] T.Suratwala, L. Wong, P. Miller, M.D. Feit, J.Menapace, R. Steele, P. Davis, D. Walmer, "Sub-surface mechanical damage distributions during grinding of fused silica" Lawrence Livermore National Laboratory, P.O. Box 808, Livermore, CA 94551 (2006)

[8] Tayyab I. Suratwala, “Materials Science and Technology of Optical Fabrication”, The American Ceramic Society and John Wiley and Sons, Hoboken NJ, USA 2018 